\title{
Dependence of Annealing Temperature on Properties of PZT Thin Film Deposited onto SGGG Substrate
}

\author{
$\mathrm{In}-\mathrm{Ho} \mathrm{Im}^{\dagger}$ \\ Department of Electrical Engineering, Shinansan University, Ansan 425-080, Korea \\ Kwang-Hyun Chung \\ Kyungwon Industry Co., Ltd., Shiheung 429-450, Korea \\ Duk-Hyun Kim \\ Department of Automatic Electrical Engineering, Yeungnam College of Science \& Technology, Daegu 705-717, Korea
}

Received May 21, 2014; Accepted July 2, 2014

$\mathrm{Pb}\left(\mathrm{Zr}_{0.52} \mathrm{Ti}_{0.48}\right) \mathrm{O}_{3}$ thin films of $1.5 \mu \mathrm{m}$ thickness were grown on $\mathrm{Pt} / \mathrm{Ti} / \mathrm{Gd}_{3} \mathrm{Ga}_{5} \mathrm{O}_{12}$ substrate by $\mathrm{RF}$ magnetron sputtering at annealing temperatures ranging from $550^{\circ} \mathrm{C}$ to $700^{\circ} \mathrm{C}$. We evaluated the residual stress, by using a William-Hall plot, as a function of the annealing temperatures of PZT thin film with a constant thickness. As a result, the residual stresses of PZT thin film of $1.5 \mu \mathrm{m}$ thickness were changed by varying the annealing temperature. Also, we measured the hysteresis characteristic of PZT thin films of $1.5 \mu \mathrm{m}$ thickness to evaluate for application of an optoelectronic device.

Keywords: PZT, Thin film, Annealing temperature, Thickness, Hysteresis, William-Hall plot

\section{INTRODUCTION}

Recently, the use of an optoelectronic device as a light modulator has been the subject of intensive research $[1,2]$. In particular, magneto-optic spatial light modulators (MOSLMs), which consist of an upper electrode, lead zirconate titanate $\left(\mathrm{Pb}\left(\mathrm{Zr}_{\mathrm{x}} \mathrm{Ti}_{1}\right.\right.$ $\left.{ }_{x}\right) \mathrm{O}_{3}$, (PZT)) thin film, a bottom electrode, a magnetic optic layer (garnet film) and a substrate, have been given particular attention due to the high switching speed of about 15 nanoseconds. In the device, PZT thin film stresses the magnetic optic layer when applying a voltage to the PZT thin film, and magnetization switching in the magnetic optic layer is simultaneously induced The PZT thin film, in the MOSLM device, has been widely used over the past few decades in actuator, memory, and sensor devices due to its low coercive field, high remnant polarization,

${ }^{\dagger}$ Author to whom all correspondence should be addressed:

E-mail:iminho@sau.ac.kr

Copyright (C2014 KIEEME. All rights reserved. This is an open-access article distributed under the terms of the Creative Commons Attribution Non-Commercial
License (http:////reativecommmons.org/licenses/by-n/3.0) which permits unrestricted noncommercial use,

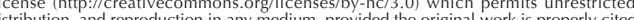

high dielectric constant and high Curie temperature. Therefore, much research has been conducted on various substrates for a range of applications [3,4].

However, PZT thin film has limitations, whereby the evaporation of $\mathrm{Pb}$ during the manufacturing process causes inhomogeneity in the composition of the PZT thin film and cracks on the PZT thin film can be generated by the mismatch of thermal expansion coefficient between the PZT thin film and the substrate. Therefore, the suppression of the compositional change and the cracks in growing PZT thin film on a substrate needs to be considered. In general, MOSLM devices use $\mathrm{Gd}_{3} \mathrm{Ga}_{5} \mathrm{O}_{12}$ (SGGG) substrates because the SGGG substrate has a similar thermal expansion coefficient (TEC), $9.2 \times 10^{-6} / \mathrm{K}$ [5], as that of PZT thin film, $7.0 \times 10^{-6} / \mathrm{K}[6]$. In the case of growing PZT thin film on an SGGG substrate, we can expect residual tensile stress and surface cracking due to the structural mismatch and thermal mismatch between the PZT thin film and SGGG substrate.

In this paper, we fabricated PZT thin film on Pt/Ti/glass and SGGG substrates using the sputtering method. In addition, we investigated the structural property of PZT thin film as a function of annealing temperature. 
Table 1. Sputtering conditions of PZT thin film.

\begin{tabular}{cc}
\hline Parameters & Values \\
\hline Target & $\mathrm{Pb}_{1.2}\left(\mathrm{Zr}_{0.52} \mathrm{Ti}_{0.48}\right) \mathrm{O}_{3}$ \\
\hline Substrates & $\begin{array}{c}\text { Corning } \# 1737(\mathrm{Quartz}) \\
\text { or SGGG }\left(\mathrm{Gd}_{3} \mathrm{Ga}_{5} \mathrm{O}_{12}\right)\end{array}$ \\
\hline Sputtering power [W] & 100 \\
\hline B.G. pressure [Torr] & $1 \times 10^{-7}$ \\
\hline Ar gas pressure [Torr] & $5 \times 10^{-3}$ \\
\hline Substrate temperature $\left[{ }^{\circ} \mathrm{C}\right]$ & $\mathrm{R} . \mathrm{T}$. \\
\hline Deposition time [min.] & $1 \sim 4$ \\
\hline Annealing temperature [ $\left.{ }^{\circ} \mathrm{C}\right]$ & $550 \sim 700$ \\
\hline Annealing time [min.] & 10 \\
\hline
\end{tabular}

\section{EXPERIMENTS}

PZT thin films were deposited onto a Corning \#1737 (Quartz) or (110) SGGG substrate by RF magnetron sputtering with an $\mathrm{Ar}$ pressure of $0.4 \mathrm{~Pa}$. The $\mathrm{Pb}_{1.2}\left(\mathrm{Zr}_{0.52} \mathrm{Ti}_{0.48}\right) \mathrm{O}_{3}$ target with a morphotrophic composition of $\mathrm{Zr} / \mathrm{Ti}=52 / 48$ was used for PZT thin film deposition to compensate $\mathrm{Pb}$ evaporation for the evaporation and annealing process. The structures using Pt/Ti/\#1737 or SGGG in this paper were composed of a Pt bottom electrode (thickness $300 \mathrm{~nm}$ ), a Ti layer (thickness $10 \mathrm{~nm}$ ), and \#1737 or SGGG substrates (0.5 mm thickness), namely a Pt/Ti/\#1737 or (110) SGGG substrate. The deposition of the PZT thin film on the two types of substrates was performed under an RF power of 100W. In order to evaluate the dependence of PZT thin film on the annealing temperature, we conducted annealing of the deposited PZT films at temperatures ranging from 550 to $700^{\circ} \mathrm{C}$ for 10 minutes in an electric furnace.

The microstructure of the deposited PZT thin films was observed using a microscope and SEM, and the crystalline structure was measured using an X-ray diffractometer (XRD). From XRD data, the residual stress of the PZT thin film deposited at different annealing temperatures was calculated using a William and Hall curve. The P-E hysteresis curves of films with different thicknesses were investigated using a Sawyer-Tower circuit. The displacement property of the specimen was measured using Laser displacement analysis.

\section{RESULTS AND DISCUSSION}

\subsection{SEM comparison of PZT thin films deposited on different substrates}

Figure 1 shows the SEM surface morphology of PZT thin films deposited on Corning \#1737 (Quartz) and SGGG substrates at annealing temperatures of $650^{\circ} \mathrm{C}$ and $700^{\circ} \mathrm{C}$, respectively. As shown in Fig. 1, the PZT thin films on the Corning \#1737 substrate showed delamination from the substrate and cracking on the PZT film, regardless of annealing temperatures. However, the PZT thin films on the SGGG substrate did not show delamination and cracking on the PZT film, despite the variation of annealing temperatures. This can be explained by the difference of thermal expansion coefficient between the Corning \#1737 (Quartz) substrate of $0.3 \times 10^{-6} / \mathrm{K}$, the SGGG substrate of $9.2 \times 10^{-6} / \mathrm{K}$, and the PZT thin films of $7.0 \times 10^{-6} / \mathrm{K}$. Therefore, SGGG substrate can be used for growing PZT thin film without defects.

\subsection{XRD analysis}

Figure 2 shows the thickness variation of PZT thin film on SGGG substrate as a function of sputtering time at room tem-

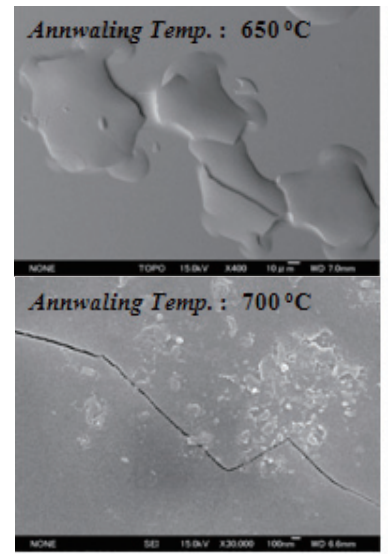

(a)

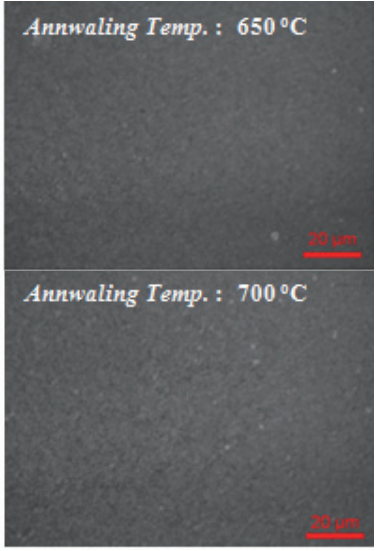

(b)
Fig. 1. SEM surface morphology of PZT thin films on Pt/Ti/. (a) \#1737 and (b) SGGG substrates.

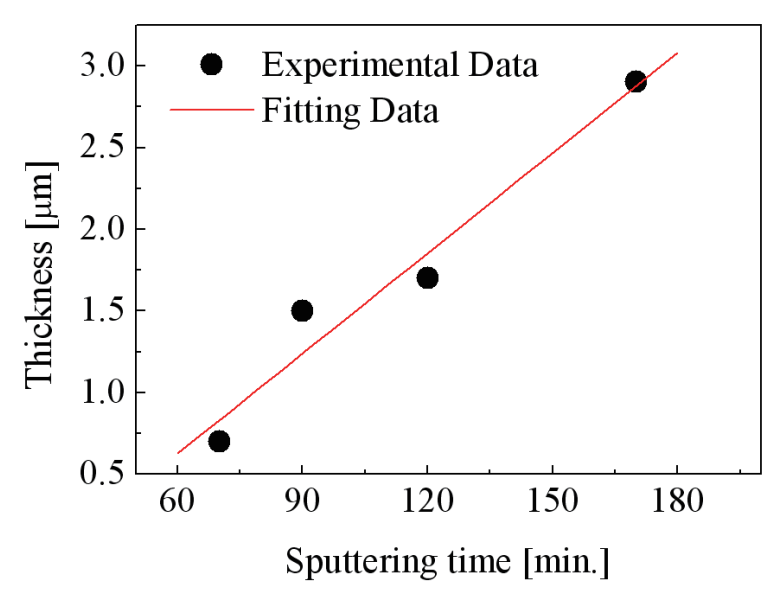

Fig. 2. Thickness variation of PZT thin films on SGGG substrate as a function of sputtering time.

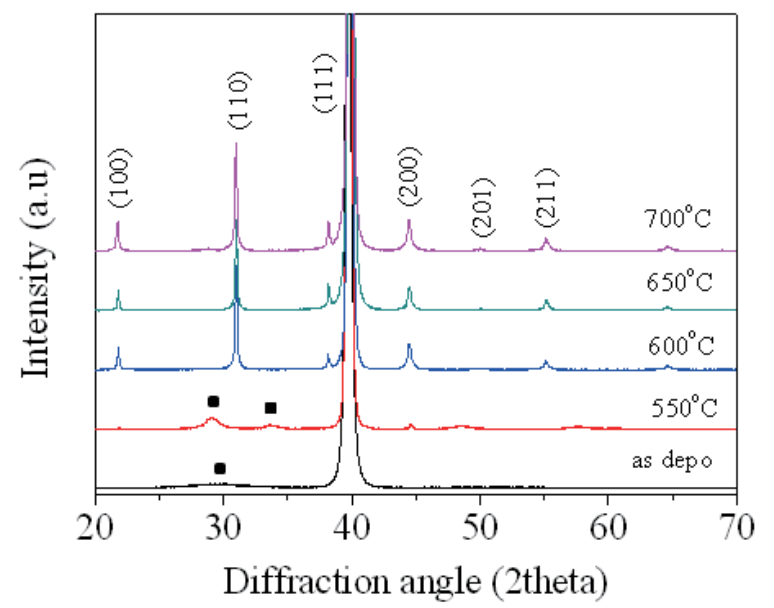

Fig. 3. XRD patterns of PZT thin films on SGGG substrate as a function of annealing temperature.

perature. The figure shows that the thickness of the PZT thin film is proportional to sputtering time.

Figure 3 shows the XRD patterns of PZT thin films deposited on Pt/Ti/SGGG substrate as a function of annealing tempera- 


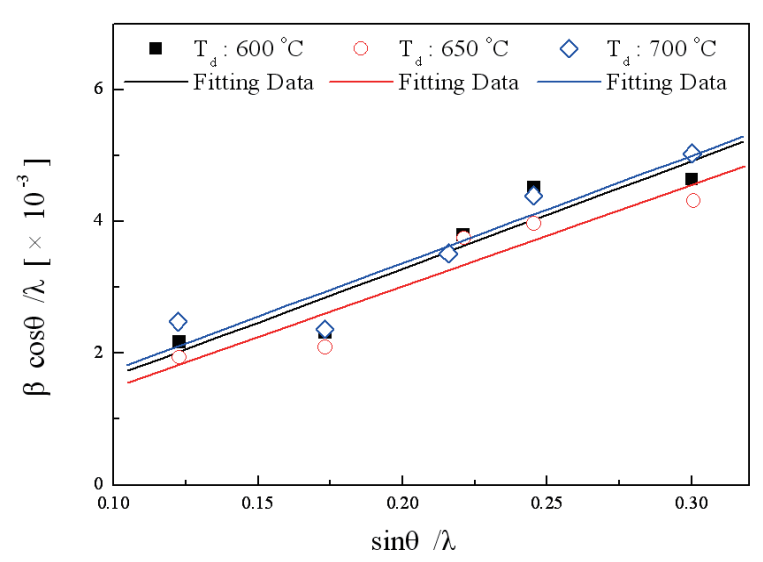

Fig. 4. XRD patterns of PZT thin films on SGGG substrate as a function of annealing temperature.

tures. Figure 3 shows that the reflection from the $\mathrm{Pb}$ dominated pyrochlore peak (expressed as a solid rectangle) present in the as-deposited PZT thin film and the PZT thin film annealed at $550^{\circ} \mathrm{C}$ due to the excess of $\mathrm{Pb}$. However, the PZT film on SGGG annealed at temperatures ranging from $600{ }^{\circ} \mathrm{C}$ to $700^{\circ} \mathrm{C}$ showed pure perovskite PZT peaks. These results show that the crystalline phase of PZT film on Pt/Ti/SGGG substrate can be greatly affected by annealing temperature. When the annealing temperature was increased from $550^{\circ} \mathrm{C}$ to $700^{\circ} \mathrm{C}$, the intensity of the perovskite PZT peak was greatly increased, as shown in Fig. 3.

Figure 4 shows the relationship between $\beta \cos \theta / \lambda$ and $\sin \theta / \lambda$, using a William and Hall curve [7], to investigate the stress of the deposited PZT films with different annealing temperatures, obtained from the FWHM of XRD data.

$$
\frac{\beta \cos \theta}{\lambda}=\frac{1}{\varepsilon}+\frac{\eta \sin \theta}{\lambda}
$$

$$
\begin{aligned}
& \text { where, } \beta: \text { FWHM [radian] } \\
& \theta: \text { Peak values } \\
& \lambda: \text { Wavelength of X-ray } \\
& \varepsilon: \text { Average grain size } \\
& \eta: \text { Average stress of films }
\end{aligned}
$$

From this plot, we can evaluate the stress of the PZT thin films on SGGG by calculating the gradient of lines. The stress values, $\eta$, of the PZT thin films on SGGG annealed at $600{ }^{\circ} \mathrm{C}, 650^{\circ} \mathrm{C}$ and $700^{\circ} \mathrm{C}$ were $0.01632,0.01534$ and 0.01630 , respectively. This means that the PZT thin film deposited at $650^{\circ} \mathrm{C}$ has the lowest stress in this annealing condition. In particular, the stress value, $\eta$, of the PZT thin film annealed at $700 \mathrm{oC}$ increased compared with that of PZT thin film deposited at $650^{\circ} \mathrm{C}$. It can be considered that the fluctuation of the composition in the PZT thin film occurred due to high annealing temperature, as reported by Aoki [8].

\subsection{Polarization vs electric field}

The polarization vs electric field (P-E) curves obtained by various annealing temperatures are shown in Fig. 5. As shown in Fig. 5, the saturation of hysteresis loops occurred in all PZT thin films on SGGG substrate, regardless of annealing temperature.

Figure 6 shows the remanent polarization (Pr) and coercive

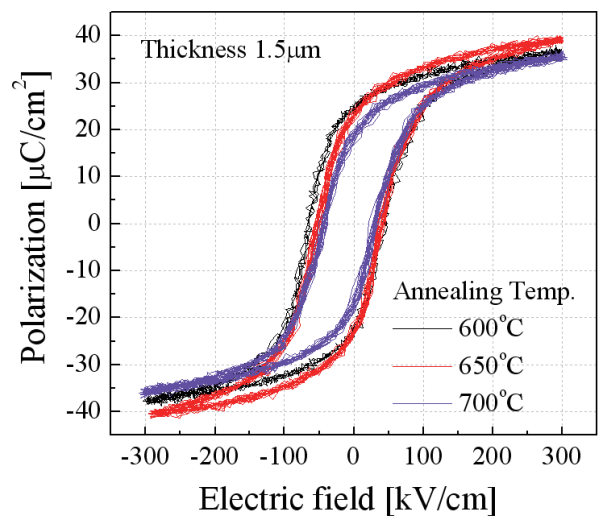

Fig. 5. Hysteresis loops of PZT thin films on SGGG substrate as a function of annealing temperature.

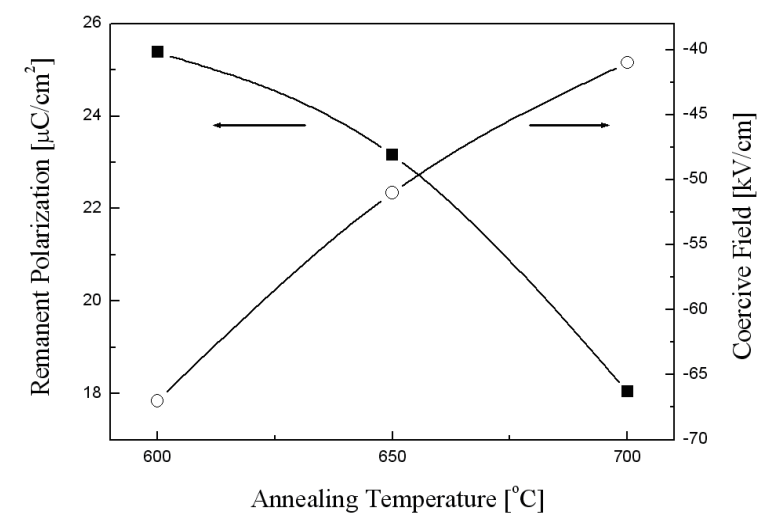

Fig. 6. Remanent polarization and coercive field of PZT thin films as a function of annealing temperature.

field (Ec) of PZT thin films on SGGG as a function of annealing temperature. When the annealing temperature was increased from 600 to $700^{\circ} \mathrm{C}$, the remanent polarization (Pr) values of PZT thin films decreased from $25.38 \mu \mathrm{C} / \mathrm{cm}^{2}$ to $18.04 \mu \mathrm{C} / \mathrm{cm}^{2}$. Also, the coercive field (Ec) values of PZT thin films increased with annealing temperatures. It is well known that a device with high remanent polarization and low coercive field has an advantage in application for a high speed memory device due to a low switching energy [9].

\section{CONCLUSIONS}

We investigated the dependence of annealing temperature on the characteristics of PZT thin film $(1.5 \mu \mathrm{m})$ on Pt $(300 \mathrm{~nm})$ / $\mathrm{Ti}(10 \mathrm{~nm})$ / Corning \#1737 (Quartz) or $\mathrm{Gd}_{3} \mathrm{Ga}_{5} \mathrm{O}_{12}$ substrates by RF magnetron sputtering. The PZT thin film on $\mathrm{Gd}_{3} \mathrm{Ga}_{5} \mathrm{O}_{12}$ substrates, annealed at $650{ }^{\circ} \mathrm{C}$, showed no crack and the lowest residual stress, $\eta$ of 0.01632 . Also, The PZT thin film showed the characteristics of high remanent polarization and low coercive field. Therefore, the PZT thin film on $\mathrm{Gd}_{3} \mathrm{Ga}_{5} \mathrm{O}_{12}$ substrates, annealed at $650^{\circ} \mathrm{C}$, can be applicable for use in a magneto-optic spatial light modulator and high speed memory device.

\section{REFERENCES}

[1] J. H. Park, J. Cho, K. Nishimura, and M. Inoue, Jpn. J. Appl. Phys., 
41, 1813 (2002). [DOI: http://dx.doi.org/10.1143/JJAP.41.1813].

[2] J. H. Park, K. Nishimura, M. Inoue, D.H. Lee, and J. Cho, J. Appl. Phys., 91, 7014 (2002). [DOI: http://dx.doi. org/10.1063/1.1448797].

[3] D. M. Kim, C.B. Eom, V. Nagarajan, J. Ouyang, R. Ramesh, V. Vaithyanathan and D.G. Schlom, Appl. Phys. Lett., 88, 142904 (2006). [DOI: http://dx.doi.org/10.1063/1.2185614].

[4] J. W. Lee, C. S. Park, J. H. Jo and H. E. Kim, Appl. Phys. Lett., 91, 072903 (2007). [DOI: http://dx.doi.org/10.1063/1.2771377].

[5] T. Wehlus, T. korner, S. Nowy, J. Frischeisen, H. karl, B. Stritzker, and W. Brutting, Phys. Status Solidi A, 208, 264 (2011). [DOI: http://dx.doi.org/10.1002/pssa.201026524].

[6] X. Zheng, J. Li, and Y. Zhou, Acta Materialia, 52, 3313 (2004). [DOI: http://dx.doi.org/10.1016/j.actamat.2004.02.047].

[7] G. K. Williamson and W. H. Hall, Acta Matallurgica, 1, 22 (1953), [DOI: http://dx.doi.org/10.1016/0001-6160(53)90006-6].

[8] K. Aoki, Y. Fukuda, K. Numata and A. Nishimura, Jpn. J. Appl. Phys., 33, 5155 (1994). [DOI: http://dx.doi.org/10.1143/ JJAP.33.5155].

[9] T. Yu, Y. F. Chen, Z. G. Liu, S. B. Xiong, L. Sun, X. Y. Chen and N.B. Ming, Mater. Lett., 26, 291 (1996). [DOI: http://dx.doi. org/10.1016/0167-577X(95)00242-1]. 